\title{
GENERATING A LONG-TERM SERIES OF SST AND CHLOROPHYLL-A FOR THE COAST OF IRELAND
}

\author{
G. Casal ${ }^{\text {a, } *}$, T. Furey ${ }^{\text {a }}$, T. Dabrowski ${ }^{\mathrm{a}}$, G. Nolan ${ }^{\mathrm{a}}$ \\ ${ }^{a}$ Marine Institute, Rinville, Oranmore, Co. Galway, Ireland- (gema.casal, thomas.furey, tomasz.dabrowski, glenn.nolan)@ marine.ie
}

KEY WORDS: SST, chlorophyll-a, long-term series, fisheries, Ireland

\begin{abstract}
:
The use of remote sensing has increased greatly in recent years due to technological advances and its advantages in comparison with traditional methods. In the case of Ireland however the use of these techniques is not well established and only $17 \%$ of remote sensing studies are related to marine and coastal environments. As a first step, and taking into account that fisheries and aquaculture plays an important economic and social role in Ireland, a database of Sea Surface Temperature (SST) and Chlorophyll-a (Chl-a) relating to the ICES fisheries management areas is being generated. Up to now three different products have been produced. These products correspond to the annual SST Climatology and annual SST Anomalies from 1982 to 2014, as well as the annual Chl-a Climatology taking into account the different life span of CZCS (1982-1986), SeaWIFS (1997-2010), MERIS (2002-2012) and MODIS-Aqua (2002-2014). Initially, the Chl-a Climatology was produced for each sensor individually while the creation of a continuous Chl-a series will be investigated in the future. Analysing the SST trends highlighted an increasing trend in SST values in Irish waters, a trend which was more pronounced in the northern areas $\left(+0.54^{\circ} \mathrm{C}\right.$ in the last 10 years $)$. Although there are differences between sensors, Chl-a concentration seems to present higher values in the Celtic Sea since 2009. Analysing the ICES Divisions individually highlighted that coastal areas presented the highest Chl-a concentrations, involving a clear differentiation in the optical properties of coastal and oceanic waters.
\end{abstract}

\section{INTRODUCTION}

The world's oceans have traditionally been poorly sampled using shipboard campaigns, partially due to the inherent logistical difficulties involved with shipboard sampling of such vast areas, but also due to the fact that the ocean is highly dynamic, making many oceanic features impossible to resolve adequately either temporally or spatially with shipboard sampling (IOCCG, 2009). Oceanographic satellite data solves many of these problems, and the amount of satellite oceanographic data available has expanded greatly in recent years. The continuity, global coverage, and high temporal and spatial resolution of satellite data make them an important tool for monitoring and characterizing the habitat and ecosystems that influence marine resources.

Remote-sensed variables such as Sea Surface Temperature (SST), sea surface height, ocean colour, ocean winds and sea ice, characterize critical habitats that influence marine resources. Most of the physical features that are important to ecosystems, such as ocean fronts, eddies, convergence zones, river plumes and coastal regions, cannot be resolved adequately without satellite data (IOCCG, 2009). Similarly, satellite data are crucial for resolving the timing of processes such as upwelling, harmful algae blooms (HABs) or seasonal transitions. Satellite ocean colour is particularly important, since it is the only remotely sensed property that directly measures a biological component of the ecosystem.

As an island nation the oceans are critically important in moderating Ireland's weather and climate. The benefits to society from marine ecosystems are wide-ranging and substantial, extending far beyond the commercial returns and food contribution from fisheries and aquaculture activities, providing Ireland with many non-commercial benefits such as biodiversity and mild climate (Harnessing our ocean wealth An Integrated Marine Plan for Ireland, 2012). Moreover, taking the seabed into account, Ireland is one of the largest EU States with a seabed territory more than 10 times its landmass (Harnessing our ocean wealth - An Integrated Marine Plan for Ireland, 2012). For this reason, the study of the ocean is of high priority for Ireland and the use of remote sensing can provide valuable information in this sense. However, in spite of the importance of remote sensing techniques and that they have been applied worldwide, in the case of Ireland their use is not well established. The main engagement in the remote sensing field is by Universities, but only $17 \%$ of the activity relates to marine and coastal fields (Casal and Furey, 2014). For this reason, there is a need for increased production of remote sensing products, especially in the marine domain. With this in mind, the generation of climatologies for SST and Chl-a is proposed as a starting point in the generation of basic oceanographic remotely sensed products for Irish waters.

Sea Surface Temperature (SST) acts as an indicator of the distribution of marine species and serves as a tracer of several oceanographic processes. SST also plays an important role in ocean-atmospheric interactions and in the determination of the variability of climatic conditions, both at regional and global scales (Cracknell and Hayes, 1991). These changes in temperature are likely to have profound effects on marine ecosystems both through the direct effects of temperature on physiology (e.g. on phytoplankton growth and timing; Bissinger et al., 2008) and through the effects on stratification (e.g. Holt et al. 2012). The latter affects both nutrient resupply to the upper mixed layer, and the length and timing of the growing season. Differences in the annual "average" surface temperature cycle, also measured by satellites at previously unattainable temporal and spatial scales, modify the "average" phytoplankton bloom conditions to which commercially important species have adapted their reproductive cycles (IOCCG, 2009).

Chlorophyll, the primary product of ocean-colour sensors, is a measure of marine phytoplankton biomass. Chlorophyll concentration is of high importance to understand the planetary carbon cycle. Of particular interest is the application to climate 
research: chlorophyll resides in phytoplankton, which use carbon dioxide in photosynthesis leading to a potential reduction in the atmospheric concentration of this greenhouse gas (IOCGG, 2006). Phytoplankton is responsible for approximately half the global photosynthetic uptake of carbon (Field et al., 1998). The relation between climate change and future ocean primary production is likely to be a key determinant of fish and fisheries production (Cushing, 1982).

The combination of SST and Chl-a plays also an important role in the detection of harmful algal blooms (HABs). The detection of HABs is essential for both fishing and aquaculture operations; remotely-sensed maps of chlorophyll-a concentration and SST can help with quick detection (e.g. Stumpf et al. 2003) and in the understanding of the formation of HABs (e.g. Tanga et al., 2006).

An issue to consider in the application of these products is that satellite data can be difficult to access, manipulate or process, particularly for people who have never used it before. So, the use of products generated by satellites in diverse applications can be sometimes limited by the gap between technology and users. Providing "usable" products will support a wide variety of final users and applications and will increase scientific and operational output in the study of the oceans. The users could include scientists as well as education and outreach institutions, environmental agencies (e.g. conservation, coastal planning), policy makers, and industries (IOCCG, 2006).

Taking into account this background, the main objective of this work is to present the first step in the generation of basic oceanographic parameters extracted from satellites. These data will contribute to filling the gap in remote sensing products offshore Ireland, and will promote and increase future application of remote sensing data. Marine Institute fisheries scientists directly engaged in commercial stock assessment and fish and shellfish health monitoring have input to the requirements assessment, which assisted with determining the priority products required. Thus, during this work, a) climatologies for annual SST, SST Anomalies, and Chl-a are generated, and b) a descriptive analysis of these trends is presented, taking into account the ICES Divisions around Ireland.

\section{MATERIAL AND METHODS}

\subsection{Study area}

As an island nation the marine waters around Ireland play an important environmental, social and economic role in a European context. Situated on the margins of the NE Atlantic, the Irish marine territory is more than 10 times its landmass making Ireland one of the largest EU States taking into account its seabed territory (Harnessing our ocean wealth - An Integrated Marine Plan for Ireland, 2012).

Due to its proximity to both the European continental landmass to the east and the deeper and more exposed waters of the Atlantic to the west, Ireland presents a high oceanographic variability. Average sea surface temperatures for coastal waters to the west and south of Ireland range from $8-10^{\circ} \mathrm{C}$ in winter to $14-17^{\circ} \mathrm{C}$ in summer (Elliot, 1991). This difference is due to the movement of warm Atlantic water onto the western Irish Shelf. Average sea surface temperatures for near shore coastal waters are influenced by freshwater run-off from land and consequently tend to be colder in winter and warmer in summer (O'Boyle and Silke, 2010).
Exposed to Atlantic weather systems, average wind speeds can vary from $12 \mathrm{~m} / \mathrm{s}$ in January to $7 \mathrm{~m} / \mathrm{s}$ in June (Anon, 1999). Wind-driven action also plays a significant role in these ocean processes, mixing waters masses and shaping the coast and shallow seabed. Moreover, wind plays a significant role in determining the residual circulation of the region (e.g. Pingree and Le Cann, 1989). The currents are primarily wind driven, but in spring and summer the current flow off the west coast is enhanced by temperature differences or salinity changes in surface and bottom water masses over the shallow continental shelf, causing a layering of different water densities. The divergence of ocean currents can lead to upwelling events in open water where cold, nutrient-rich waters from the ocean depths are driven up into the surface waters (DECLG, 2013). In coastal waters the same event is caused by winds pushing surface water seaward forcing deeper water upward to replace it. In Irish waters both types of upwelling are known to occur but it is most commonly wind-driven (DECLG, 2013). Upwelling events may stimulate periodic diatom blooms.

These oceanographic conditions make the waters around Ireland very productive and consequently they support a rich and diverse range of ecosystems, habitats and species. Ireland's waters contain some of the largest and most valuable sea fisheries resources in Europe and its coast is an ideal location for finfish, shellfish and seaweed aquaculture. It is widely acknowledged that Irish waters are critically important in the life-cycle of many species. As illustrated in the Atlas of the Commercial Fisheries around Ireland (2009), the largest and most valuable migratory pelagic stocks in the Northeast Atlantic (mackerel, horse mackerel and blue whiting) all spawn off the west coast of Ireland. Large stocks of hake, anglerfish and megrim also spawn along the continental slope west and south of Ireland. There are also important herring, cod, haddock, whiting, plaice and sole spawning areas in the Irish Sea and the Celtic Sea. The shelf area and coastal waters are important nursery areas for young fish. Shellfish stocks such as prawn, crab, lobster, shrimp, scallop, whelk and cockles are also abundant regionally or locally.

To know the spatial and temporal trend of oceanographic parameters such as SST or chlorophyll are essential to study abundance and distribution of certain fish species. For this reason the study area was defined taking into account the ICESSubareas that surround the country and where the main fisheries are located (Fig.1). These areas correspond to geo-political boundaries defined by the International Council for the Exploration of the Seas (ICES).

The principal ICES areas around Ireland are Sub-area VI (composed of ICES Divisions VIa and VIb) and Sub-area VII (composed of ICES Divisions VIIa, VIIb, VIIc, VIIf, VIIg, VIIh, VIIj, and VIIk). Values of SST and chlorophyll where extracted for the two main areas West Scotland and Celtic Sea that correspond with the ICES Sub-areas VI and VII, respectively. Moreover, values of these oceanographic parameters (SST/Chl-a) were also extracted for each ICES Division individually. 


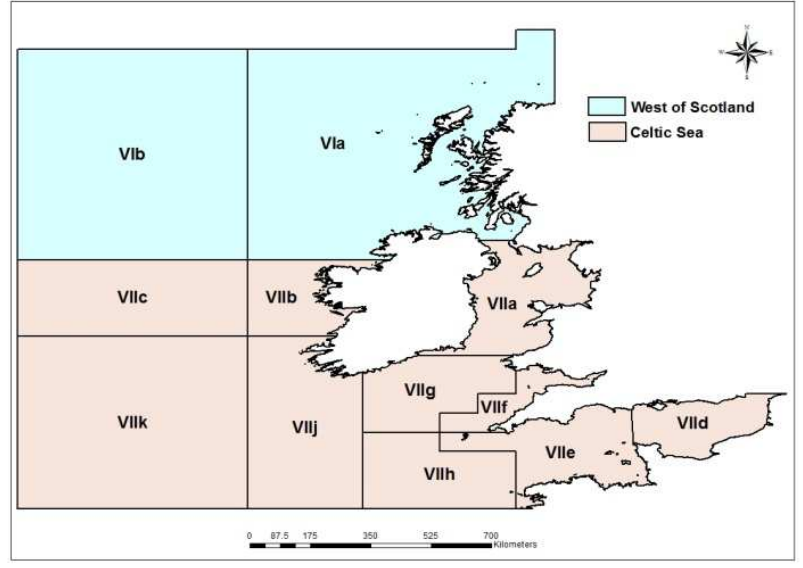

Figure 1. This map represents the ICES Divisions around Ireland that have been included in this study. Annual Mean of SST and Chl-a concentration has been extracted for each of the main areas, West of Scotland and Celtic Sea, as well as for each the ICES Division (VIa, VIb, VIIa, VIIb, VIIc, VIIf, VIIg, VIIh, VIIj, VIIk).

\subsection{Sea Surface Temperature (SST)}

Global daily optimum interpolation (OI) sea surface temperature (SST) (OI.v2), also referred as "Reynolds SST", were downloaded from the NOAA servers (http://www.ncdc.noaa.gov/oisst ) as NetCDF files covering the period from 1982 to 2014. These data are produced at the National Oceanic and Atmospheric Administration (NOAA; Reynolds et al., 2007, 2009) using in situ data from ships and buoys and includes a large-scale adjustment of satellite biases with respect to the in situ data. The NetCDF files hold several variables however, in this study only SST (Degrees Celsius), Estimated error standard deviation of analysed SST (Degrees Celsius) and SST anomalies (Degrees Celsius) have been included. The SST products have a spatial grid resolution of 0.25 degrees $(\sim 25 \mathrm{~km})$. In the OI.v1 and OI.v2 analyses an operational AVHRR product was used. Details on the algorithm can be found in May et al. (1998). The biggest challenge in retrieving SST from an IR instrument is the cloud detection problem. Once clouds have been eliminated, the SST retrieval algorithm is designed to minimize the effects of atmospheric water vapour using two or three IR channels (Reynolds et al., 2007). The SST algorithms are "tuned" using regression of SST against quality-controlled buoy data. This procedure converts the retrieval of the temperature of the "skin" (roughly micron in depth) to a "bulk" (roughly $0.5 \mathrm{~m}$ depth) SST. To make this procedure as stable as possible, the tunning procedure is done globally with several weeks of data (Reynolds et al., 2007). The OI.v2 analysis includes a preliminary correction of the AVHRR satellite data with respect to the in situ data before they are used in the OI. This initially step is necessary because the OI method assumes that the data do not contain long-term biases. The estimated error standard deviation of analysed SST provides a measure of confidence or quality of the SST data. The SST anomaly refers a departure from a reference value or long-term average. A positive anomaly indicates that the observed temperature was warmer than the reference value, while a negative anomaly indicates that the observed temperature was cooler than the reference value. The climatology used to compute the daily OISST anomalies included in the NetCDF files represents the 1971-2000 base period and is interpolated to $0.25^{\circ}$ daily grid file from the $1^{\circ}$ monthly file. This climatology is described in detail in Xue et al. (2003).
Once the files were downloaded, the daily global images were average for each year using Matlab software. Subsequently, the images were clipped into the study area and imported into ARCGIS 10.2 to calculate the mean value for each ICESSubarea and each ICES-Division (Fig.2).

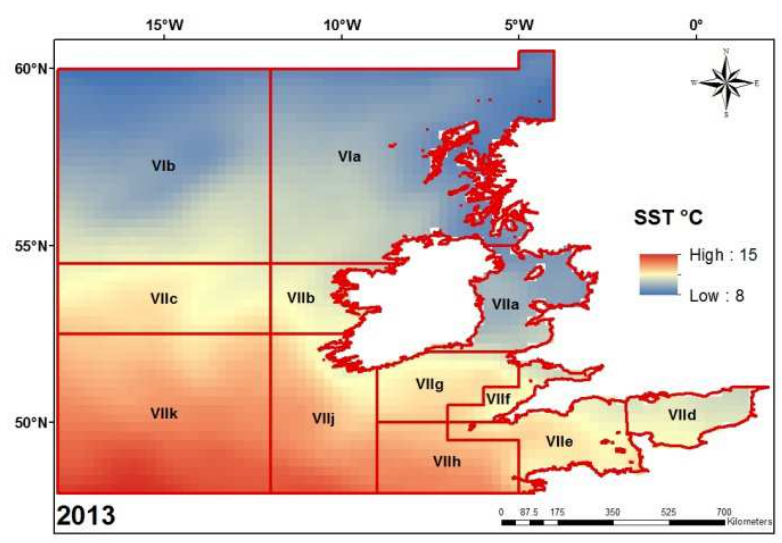

Figure 2. Map of annual SST for 2013.

In this process the average of all the pixels in the raster that belong to the same specific ICES sub-area or Division is calculated. Values of Maximum, Minimum, Standard Deviation and Range were also calculated for each of the areas. All these calculations where made without taking into account NoData values. The resulting products were exported as GeoTIFF and NetCDF files. Moreover, a database with the extracted values was created to analyse the temporal trends.

\subsection{Chlorophyll (Chl-a)}

Four missions with a multi-annual global coverage were considered in this study: the Coastal Zone Color Scanner (CZCS), the Seawing Wide Field-of-view Sensor (SeaWIFS), the MEdium Resolution Imaging Spectrometer (MERIS) and the MODerate resolution Imaging Spectrometer on board the platform Aqua (MODIS-Aqua). All four sensors are flying on polar orbiting platforms, collecting data at several wavelengths in the visible and near-infrared part of the electromagnetic spectrum, with equator crossing time between approximately 10:00 and 13:30. However, each of the sensor has a different lifespan and at the moment only MODIS-Aqua continues being operative. Due to inconsistences in the system to system performances, retrieval algorithms and calibration errors, the standard geophysical product of each sensor should not be merged as is (Arun Kumar et al., 2014). Without continuous validation for monitoring the long-term stability of satellite instruments, if the sensor calibration is not tracked and in the case of potential instrumental errors, such comparisons may lead to misinterpretation of geophysical phenomena (McClain, 1998). Taking into account these considerations the different products were analysed independently. Thus, the study spans from 1982 to 1986 using data provided by CZCS, and from 1997 to 2014 using the other sensors however, they are not completely overlapped in time. SeaWIFS covers a period from 1997 to 2010, MERIS from 2002 to 2012 and MODIS-Aqua from 2010 to 2014

At a first step, annual mean Chlorophyll-a concentration $\left(\mathrm{mg} / \mathrm{m}^{3}\right)$ with a spatial resolution of 0.1 degrees $(\sim 9 \mathrm{~km})$ was downloaded from the http://oceancolor.gsfc.nasa.gov .This data are provided by the Ocean Biology Processing Group (OBPG) at NASA's Goddard Space Flight (GSFC). Algorithms are applied to the radiance data from the sensors to produce Level 2 
geophysical products. The operational algorithm for deriving near-surface chlorophyll-a concentrations updated version (OC, O'Reilly et al. 2000) developed for SeaWIFS and adapted to the other sensors. The algorithm form describes the polynomial best fit that relates the log-transformed geophysical variable to a logtransformed ratio of remote sensing reflectance.

In this study, the L3 Standard Mapped Images (SMI) products were analysed. These products are created from the corresponding Level 3 binned products. Each SMI file contains a Plate Carrée, pixel-registered grid of floating-point values (or scaled integer representations of the values) for a single geophysical parameter. A colour look-up table is also provided in each file that may be used to generate an image from the data. Thus, each SMI product represents data binned over the period covered by the parent product. The arithmetic mean is used in each case to obtain the values for the SMI grid points from the binned data products. Each SMI product contains one image of a geophysical parameter and is stored in one physical HDF file.

The global images were imported into ArcGIS 10.2 and resized to the study area (Fig.3). Subsequently, values higher than 30 $\mathrm{mg} / \mathrm{m}^{3}$ were eliminated from the analysis. Values of higher concentrations can be reached during phytoplankton blooms in Irish waters (Silke et al., 2005) but these events occur at one precise moment within the year and they cannot be visible in the annual means. Thus, stand out values of pixels located close to the coast and where extraction algorithms show more problems can be reduced. Subsequently, Mean, Maximum, Minimum, Standard Deviation and Range values were calculated. The extraction process was the same than the one used for the SST data.

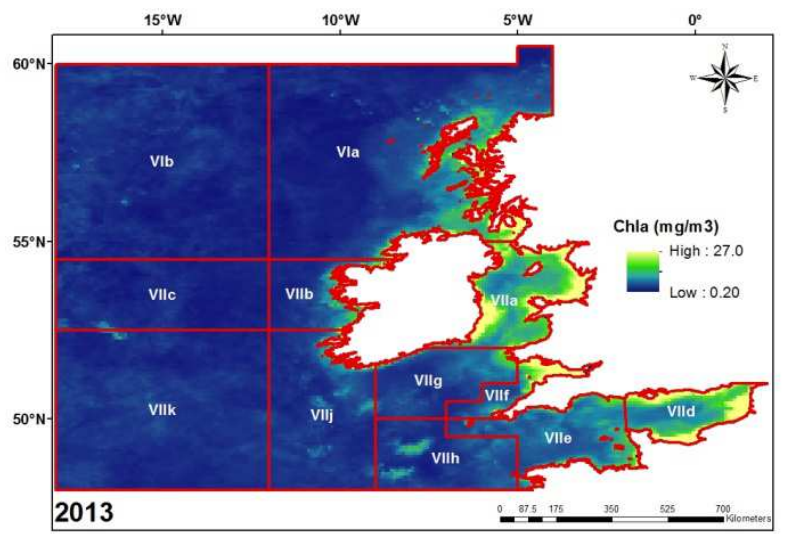

Figure 3. Map of chlorophyll-a concentration for 2013

\section{RESULTS AND DISCUSSION}

Over the last decades, many space sensors have been launched achieving regional or global coverage and providing unprecedented views of the marine systems. As a result, the applications of satellite imagery have considerably expanded, becoming a major component of marine biogeochemical and ecological programmes (IOCCG, 2008).

At this moment, and as a first step in the generation of a more complete database, three different products are presented. The analysis included here although mostly descriptive, presents a significant step in developing the understanding of oceanographic processes in Ireland's coastal waters, due in part to their spatial and temporal continuity which is absent in ship based field campaigns.

\subsection{Annual SST Climatology}

The analysis of annual SST climatology showed West Scotland presented colder waters than the Celtic Sea during the whole analysed period (Fig. 4). The difference between both zones reached almost $2^{\circ} \mathrm{C}$ if the average of the whole period is taken into account. During these 33 years, periods of lower temperatures alternated with periods of higher temperatures and these patterns seem to be contemporary in both zones. Going into further detail, the lowest mean SST ( \pm standard deviation) in the West of Scotland was $10.18^{\circ} \mathrm{C}( \pm 0.57)$ reached in 1986 and the highest was $11.48^{\circ} \mathrm{C}( \pm 0.50)$ reached in 2003 . For the Celtic Sea the lowest mean SST was $11.8^{\circ} \mathrm{C}( \pm 0.17)$ reached in 1986 and the highest was $13.45^{\circ} \mathrm{C}( \pm 0.15)$ reached in 2007 . Interestingly, these data are coincident with El Niño (19861987) and La Niña (2007-2008) events, however this relationship should be studied more in detail. In spite of the alternation of low and high mean SST within these years, there is a clear increasing trend in both zones. If the last 10 years are taken into account, the Celtic Sea has undergone $0.33^{\circ} \mathrm{C}$ $( \pm 0.02$, $)$ with regard to the average of the rest of the years, while in the West of Scotland this trend is stronger, reaching $0.54{ }^{\circ} \mathrm{C}$ $( \pm 0.04)$. These results are coincident with the global SST trend and with the general trend obtained in other studies carried out in Irish waters (Irish Ocean Climate and Ecosystem Status Report, 2009) even though a different period was investigated.

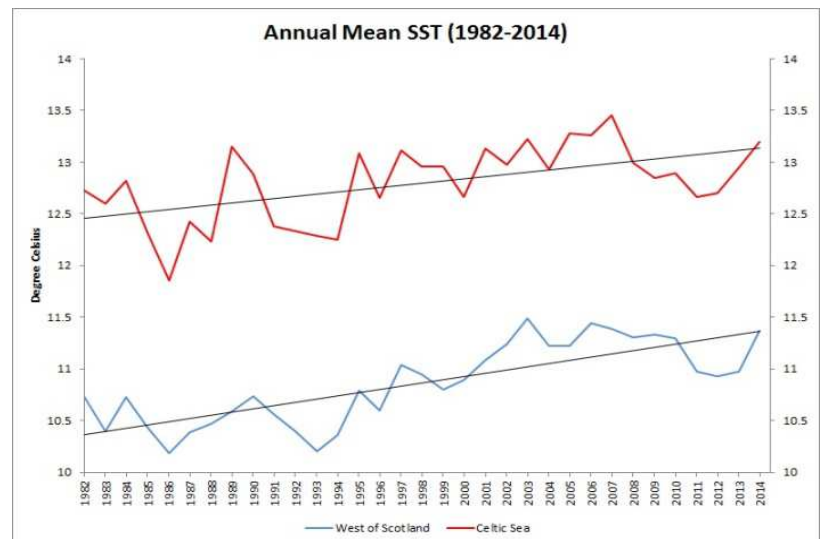

Figure 4. Annual SST for the West Scotland (Sub-area VI) and Celtic Sea (Sub-area VII).

Regarding the mean SST in each ICES division, the same trend was observed in the two zones, West of Scotland and Celtic Sea, however a higher interannual variability in SST values was noted. As it was expected the ICES Divisions that showed the lower SST values corresponded with the ones located in the West of Scotland zone. However, the lowest mean SST, $10.02^{\circ} \mathrm{C}( \pm 0.61)$, was reached in the Division VIIa in 1986 . This Division, VIIa, corresponds to the Irish Sea and it presents values very similar to the regions located in the North. On the other hand, the ICES sub-areas that present the highest mean SST values correspond to VIIk, VIIh and VIIj, located in continuous areas in the most Southern region. These results are coincident with the ones obtained by Cannaby and Hüsrevoglu (2009). The highest mean SST corresponds to $14.01^{\circ} \mathrm{C}( \pm 0.60)$ and was reached in the ICES Division VIIk, named as South of Ireland-West, in 2005. Both data are coincident again with El Niño (1986-1987) and La Niña (2005-2006) events.

The annual SST climatology is complemented with estimated error standard deviation data for every year. These data give information about confidence and quality of annual SST. This error showed values ranging between $0.14^{\circ} \mathrm{C}$ and $0.21^{\circ} \mathrm{C}$ for the 
two main zones and between $0.13^{\circ} \mathrm{C}$ and $0.22^{\circ} \mathrm{C}$ for the ICESsubareas. The mean error for both zones, West of Scotland and Celtic Sea, as well as for the ICES subareas was $0.16^{\circ} \mathrm{C}$ demonstrating good quality of the data. The year with the highest estimated error standard deviation was 1995 $\left(0.21^{\circ} \mathrm{C} \pm 0.02\right)$. The ICES sub-areas with the highest error during this period were VIIa (Irish Sea) and VIIf (Bristol Channel) with $0.18^{\circ} \mathrm{C}( \pm 0.02)$. Both of them are areas of small extension and close to the coast involving complex oceanography and high suspended sediment concentrations (e.g. Kirby and Parker, 1983; Proctor et al, 2001). These considerations should be taking into account by users in future application of the data.

\subsection{Annual SST Anomalies}

The analysis of the SST Anomalies confirmed the increasing SST trend showed by the analysis of the annual SST data. The trend is similar in both zones with the exception of 1989 and 1996. In these dates the SST anomalies are positive for the Celtic Sea but negative for the West of Scotland. They were especially strong in 1989 where SST Anomaly reached $0.51{ }^{\circ} \mathrm{C}$ $( \pm 0.19)$ for the Celtic Sea and $-0.01{ }^{\circ} \mathrm{C}( \pm 0.24)$ for West of Scotland. The average SST anomaly for the last 10 years was $0.35^{\circ} \mathrm{C}( \pm 0.22)$ for the Celtic Sea and $0.51^{\circ} \mathrm{C}( \pm 0.19)$ for West Scotland. For the rest of the years (1982-2004) the average SST anomalies were of $0.05{ }^{\circ} \mathrm{C}( \pm 0.2)$ for the Celtic Sea and $0{ }^{\circ} \mathrm{C}$ $( \pm 0.19)$ for West of Scotland, indicating that the increasing trend in SST has occurred particularly in the last 10 years (Fig.5). This confirms the results obtained in the analysis of SST that reports a higher warmer trend in the Northern areas.

By analysing the SST anomalies in every ICES division it can be observed that the trend during the analysed years is similar to the trend obtained in West Scotland and Celtic Sea. However, in the last 5 years some of the ICES Divisions showed negative values not detectable in the analysis of the main areas (Fig.5). This is despite the fact that a positive trend exists since 1997 in the West Scotland and Celtic Sea. Taking into account the whole period analysed, the ICES Division that presents the highest SST Anomaly corresponds to VIId with a value of $0.25^{\circ} \mathrm{C}( \pm 0.14)$, and the lowest corresponds to VIIe with $0.08^{\circ} \mathrm{C}$ $( \pm 0.10)$. This result needs to be investigated more in detail as both areas correspond to the eastern and western part of the English Channel, respectively, and it is surprising that two areas located adjacent to each other present such differences in SST anomalies.

Over the past 20 years the North Atlantic has warmed significantly and this is especially true for the subpolar North Atlantic (between 50-70 N), where Ireland and its surrounding waters are located. It is associated with a significant weakening of the subpolar North Atlantic Circulation (Häkkinen and Rhines, 2004). The recent changes in North Atlantic heat content represent a return to the positive phase of the Atlantic Multidecadal Oscillation, which may have impacts on North American and European Climate (Robson et al., 2012).
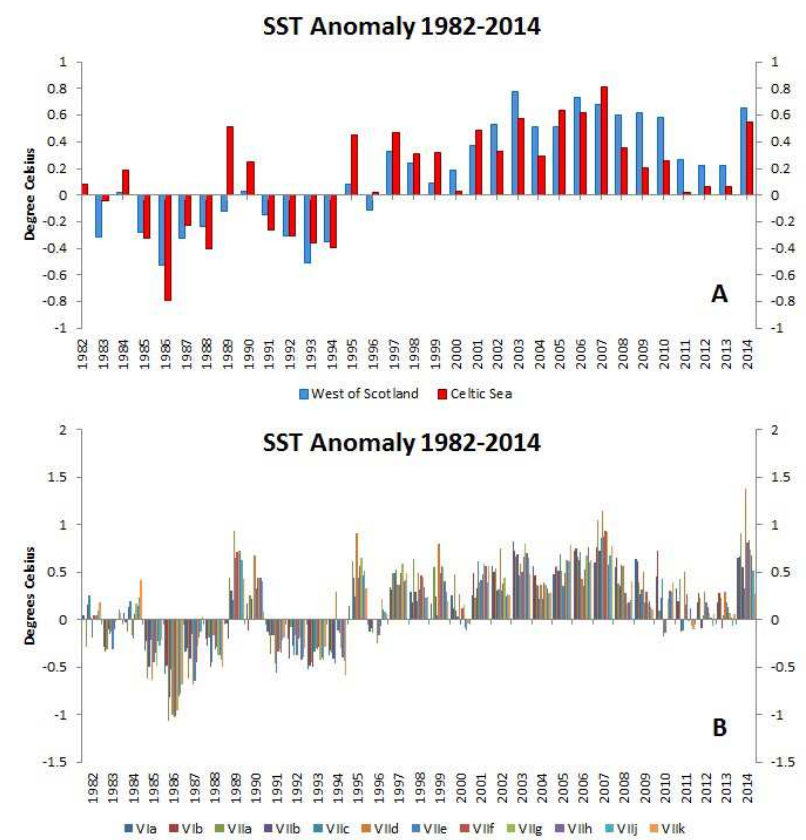

Figure 5. A) Annual SST Anomalies for the two main zones analysed in the study: West of Scotland and Celtic Sea. B)

Annual SST Anomalies for every ICES Division. The climatology used to compute the daily OISST anomalies used in this study represents the 1971-2000 base period.

\subsection{Annual Chl-a Climatology}

In order to construct a continuous time series of bio-optical and geophysical variables, the ocean colour community currently relies on a number of individual missions launched by several space agencies, with radiometric sensors from various manufactures and with slightly different technical specifications (Djavidnia et al. 2010). Preliminary global inter-comparison exercises have already been conducted (e.g. Dierssen, 2010; Kahru et al., 2014). These studies underlined significant differences between products, even though the broad patterns and general statistics usually appeared consistent. Some preliminary analyses show that this inconsistency is also observed for our study zone. For this reason and as first step it was decided to analyse the data series considering every sensor individually.

The analysis of annual Chl-a concentration for West of Scotland and Celtic Sea did not show a clear trend or clear differences between the two areas within the different periods for all the sensors. However, since 2009 chlorophyll concentrations are higher in the southern waters, Celtic Sea. The data registered by CZCS do not present temporal continuity with any of the other sensors included in the study, for this reason it was decided to rule out its data in the continuous long term series. The results presented here are more focused on the comparison of the sensors which are overlapped in time.

At a first glance, SeaWIFS and MODIS-Aqua present more similar results while MERIS seems to underestimate the values. Taking into account SeaWIFS and MODIS-Aqua the highest Chl-a concentrations where reached in 2004, both sensors are coincident, in the West of Scotland with concentrations of $1.36 \mathrm{mg} / \mathrm{m}^{3}( \pm 0.59)$ and $1.38 \mathrm{mg} / \mathrm{m}^{3}( \pm 0.96)$ respectively. MERIS registered a chlorophyll concentration for this year of $0.93 \mathrm{mg} / \mathrm{m}^{3}( \pm 0.56)$. The lowest chlorophyll concentrations registered by MODIS-Aqua, $0.65 \mathrm{mg} / \mathrm{m}^{3}$ ( \pm 0.90$)$ corresponds 
to the same zone, West Scotland, in 2013 (Fig.6). It is not possible to compare this data with SeaWIFS or MERIS as they were not registering data during this period. The analysis of the two main zones during the whole period showed that there is not an established trend, with the mean chlorophyll concentrations observed around $1 \mathrm{mg} / \mathrm{m}^{3}$.

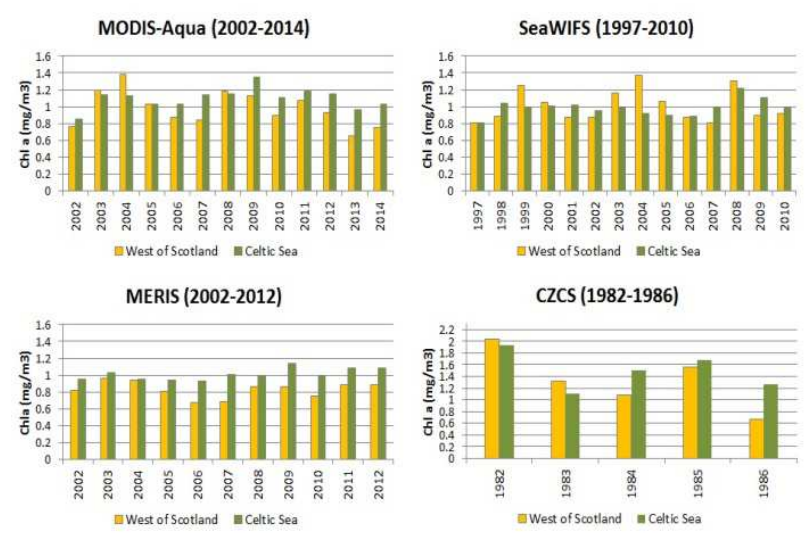

Figure 6. Chl-a concentrations for the West of Scotland and Celtic Sea. To avoid the variations in calibration strategies and algorithms the data are presented and analysed individually for each sensor.

The analysis of Chl-a concentrations in the ICES Divisions showed much more variability (Fig.7). Analysing the whole period for each sensor, the ICES Divisions that showed the lowest concentrations were VIIc and VIIk. These areas correspond with open waters in the West (VIIc) and South-West (VIIk) of Ireland. The Division VIb also presented low concentrations, this area corresponds also with open waters in the North West of Ireland but its Chl-a concentrations are a bit higher. The Chl-a concentrations for these areas, according to MODIS-Aqua, reached in the last 5 years a mean ( \pm standard deviation) of $0.46 \mathrm{mg} / \mathrm{m}^{3}( \pm 0.09), 0.47 \mathrm{mg} / \mathrm{m}^{3}( \pm 0.10)$ and 0.57 $\left( \pm 0.18 \mathrm{mg} / \mathrm{m}^{3}\right)$ in VIIc, VIIk and VIb repectively. On the other hand, the ICES sub-areas that present the highest concentrations are VIIa and VIId followed by VIIf. These areas are located close to the coast and correspond with the Irish Sea, Eastern English Channel and Bristol Channel. The Chl-a concentrations using MODIS-Aqua data reached in the last 5 years a mean $( \pm$ standard deviation) of $3.12 \mathrm{mg} / \mathrm{m}^{3}( \pm 2.45), 2.85 \mathrm{mg} / \mathrm{m}^{3}( \pm 2.01)$ and $2.25 \mathrm{mg} / \mathrm{m}^{3}( \pm 1.77)$ respectively.

These results showed that Case 1 and Case 2 waters are present in the study zone, and this situation should be considered when remote sensing data are used. Case 2 waters are more complex than Case 1 in their composition and optical properties. For this reason the interpretation of its optical signal can therefore be rather difficult. To date, remote sensing of ocean colour has focussed largely on the relatively-simple Case 1 waters, and it is well recognized that standard algorithms in use today for chlorophyll retrieval from satellite data break down in Case 2 waters (IOCCG, 2000). Other uncertainties in satellite data exist between sensors, especially in retrieval of medium to high chlorophyll values, which may affect the estimation of trends and may be biasing our interpretation of biomass and productivity in coastal waters, despite the large number of observations used in the development of the standard NASA ocean colour algorithms (Kahu et al., 2014). Consequently, it is essential to test the derived products with respect to each sensor and to know their performance.
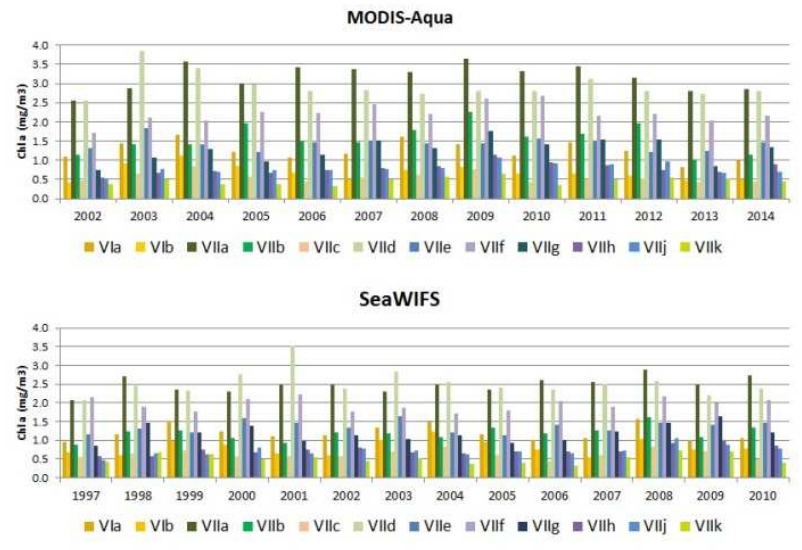

MERIS

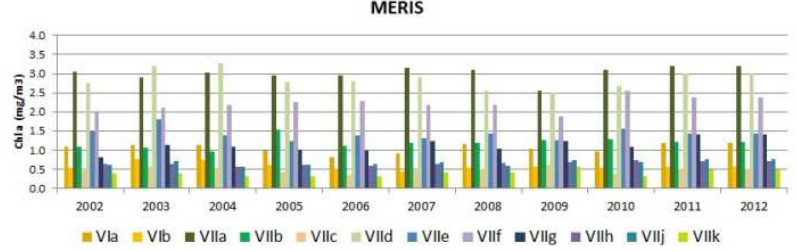

Figure 7. Chlorophyll-a concentration for the different ICES Divisions. Data presented are extracted from MODIS-Aqua, SeaWIFs and MERIS that present a temporal continuity with regard to each other.

Despite the potential of satellite data to dramatically improve the monitoring of marine waters and its resources, several constraints to its use have been identified by the operational community, such as inadequate data access and an inadequate system of analysing and disseminating this information to the communities outside the research community. The challenge is to develop better links between the remote sensing world and the communities who can use this data e.g. scientist, the fishing and aquaculture industries, management and policy makers (IOCCG, 2009).

\section{CONCLUSIONS}

Although more analyses need to be done and more products need to be created, the results presented here represent a small step in the application of remote sensing data to the marine science community in Ireland. During this work annual climatologies of SST and Chl-a have been generated. In spite of the simplicity of the analysis these products themselves are new and unique for Ireland's waters. These data will complement the field campaigns of oceanographic vessels providing spatial and temporal continuous data of vast areas not achievable by ships.

Satellite data can be difficult to access, manipulate and process, particularly for people who have never used it before. These data and future products will be publicly and easily accessible, in standard data formats such as GeoTIFF, NetCDF or image format (e.g. jpg), with associated tables with the data extracted for every ICES Sub-area and Division. In Ireland, many potential users do not have the infrastructure to download and process, or even view remote sensed data. Development, delivery, and availability of the data in user friendly formats will promote the use and increase the application of the products generated, as well as raise awareness of remote sensing product application in Irish marine resource management.

Of special interest is the potential application of SST and Chl-a data to fisheries. The scale and temporal extent of this remotesensing data makes them suitable for ecosystem studies, 
especially to study the role of the environment on species dynamics, fisheries assessment, management or operations. It is possible to locate fish-feeding grounds from SST and chlorophyll images generated from satellite data through the detection of oceanic features or gradients. Thermal or colour gradients, arising from circulation of water masses, often indicate areas of high biological productivity and in turn areas of high probability of finding fish. Remote sensing can also be applied usefully to aquaculture, particularly to provide information on where to locate fish and shellfish farms, taking into account factors such as water quality, transport of nutrients and sea surface temperature. The use of satellite data can be also invaluable in the estimation of harmful algae blooms using the monitoring of chlorophyll concentrations and SST. The prediction and quantification of these blooms can aid fishing operations, fisheries management and coastal zone management. Other applications include ecological and process studies of the ocean, or indeed climate change.

In conclusion, these data can support a wide variety of users and applications and increase scientific and operational output for oceanographic satellite measurements. Among the potential users of these products are scientists, but also education and outreach institutions, and environmental agencies (e.g. conservation, coastal planning, policy makers, and industries). Moreover, new satellites are planned to be launched in the future, among then the oceanographic Sentinel-3. Applying and understanding the previous satellite data will help to involve Ireland in the development of new products and services as the technology evolves and to get a foothold in the remote sensing field.

\section{ACKNOWLEDGEMENTS}

Authors would like to thank the Ocean Biology Processing Group (OBPG) at NASA's Goddard Space Flight (GSFC) for the processing and availability of Chlorophyll Data and National and Climatic Data Center (NOAA) for the Optimum Interpolation (OI) Sea Surface Temperature (SST) V2. Special thanks to K. Lyons for his help with Matlab scripts.

\section{REFERENCES}

Anon, 1999. Ireland's Marine and Coastal Areas and Adjacent Seas: An Environmental Assessment. Published by The Marine Institute, Rinville, Co. Galway. pp. 338.

Arun Kumar, S.V.V., Kabu, K.N., Babu, K.N., Shukla, A.K. 2014. Comparative analysis of Chlorophyll-a distribution form SeWIFS, MODIS-Aqua, MODIS-Terra and MERIS in the Arabian Sea. Marine Geodesy, 0, pp.1-18.

Atlas of the Commercial Fisheries around Ireland, 2009. Review of the Fisheries of Relevance to Ireland. Published by The Marine Institute, Rinville, Co. Galway.pp.64.

Bissinger, J.E., Montagnes, D.J.S., Sharples, J., Atkinson, D., 2008. Predicting marine phytoplankton maximum growth rates from temperature: improving on the Eppley curve using quantile regression. Limnology and Oceanography, 53 (2), pp. 487-493.

Casal, G. and Furey, T., 2014. Remote sensing for marine mapping. INFOMAR Annual Seminar, October 22-23, Waterford, Ireland.
Cracknell, A. P., Hayes, L. W. B., 1991. Introduction to Remote Sensing. London, UK, Taylor \& Francis, pp. 293

Cushing, D. H., 1982. Climate and Fisheries, 1st edition. Academic Press, London, England.

DECLG, 2013. Ireland's Marine Strategy Framework Directive Article 19 Report. Initial Assessment, GES and Targets and Indicators. Department of Environment, Community and Local Government and the Marine Institute. October 2013. 162 pp. http://www.environ.ie/en/Publications/Environment/Water/File DownLoad,34365,en.pdf

Dierssen, H.M., 2010. Perspectives on empirical approaches for ocean remote sensing of chlorophyll in a changing climate. Proc. Natl. Acad. Sci., 107(40), pp.17073-17078.

Djavidnia, S., Melin, F., Hoepffner, N., 2010. Comparison of global ocean colour data records. Ocean Sci., 6, pp.61-76.

Elliot, S.A. J., 1991. Monthly distributions of surface to bottom temperatures in the northwest European shelf sea. Cont. Shelf. Res. 11, pp.453-466.

Field, C.B., Behrenfeld, M.J., Randerson, J.T., Falkowski, P., 1998. Primary production of the biosphere: Integrating terrestrial and oceanic components. Science, 281 (5374), pp. 237-240.

Häkkinen, S., Rhines, P.B,. 2004. Decline of subpolar North Atlantic gyre circulation during the 1990s, Science, 304, pp. $555-559$.

Harnessing our ocean wealth - An Integrated Marine Plan for Ireland, 2012. Harnessing our ocean wealth. Published by The Marine Institute, Rinville, Co. Galway, pp.88.

Holt, J., Hughes, S., Hopkins, J., Wakelin, S.L., Holliday, N.P., Dye, S., González-Pola, C., Hjøllo, S.S., Mork, K.A., Nolan, G., Proctor, R., Read, J., Shammon, T., Sherwin, T., Smyth, T., Tattersall, G., Ward, B., Wiltshire, K.H., 2012. Multi-decadal variability and trends in the temperature of the northwest European continental shelf: A model-data synthesis. Progress in Oceanography, 106, pp. 96-117.

IOCCG, 2000. Remote Sensing of Ocean Colour in Coastal, and Other Optically-Complex, Waters. Sathyendranath, S. (ed.), Reports of the International Ocean-Colour Coordinating Group, No. 3, IOCCG, Dartmouth, Canada.

IOCCG, 2006. Remote Sensing of Inherent Optical Properties: Fundamentals, Tests of Algorithms, and Applications. Lee, Z.P. (ed.), Reports of the International Ocean-Colour Coordinating Group, No. 5, IOCCG, Dartmouth, Canada.

IOCCG, 2008. Why Ocean Colour? The Societal Benefits of Ocean-Colour Technology. Platt, T., Hoepffner, N., Stuart, V. and Brown, C. (eds.), Reports of the International Ocean-Colour Coordinating Group, No. 7, IOCCG, Dartmouth, Canada.

IOCCG, 2009. Remote Sensing in Fisheries and Aquaculture. Forget, M.-H., Stuart, V. and Platt, T. (eds.), Reports of the International Ocean-Colour Coordinating Group, No. 8, IOCCG, Dartmouth, Canada.

Irish Ocean Climate and Ecosystem Status Report, 2009. Nolan, G., Gillooly, M., Whelan, K. (eds) ISBN: 978-1-902895-40-6 
Kahru, M., Kudela, R.M., Anderson, C.R., Manzano-Sarabia, M., Mitchell, B.G., 2014. Evaluation of satellite retrievals of ocean chlorophyll-a in the California Current. Remote Sens., 6, pp. 8524-8540.

Kirbi, R., Parker, W.R., 1983. Distribution and Behaviour of Fine Sediment in the Severn Estuary and Inner Bristol Channel, U.K. Canadian Journal of Fisheries and Aquatic Sciences, 40(1), pp.83-95.

May, D. A., Parmeter, M. M., Olszewski, D. S., McKenzie, B. D., 1998. Operational processing of satellite sea surface temperature retrievals at the Naval Oceanographic Office. Bull. Amer. Meteor. Soc., 79, pp. 397-407.

McClain, C.R., Cleave, M.L., Feldman, G.C., 1998. Science quality SeaWIFS data for global biosphere research. Sea Technology 39 (9), pp.10-16.

O’Boyle, S., Silke, J., 2010. A review of phytoplankton ecology in estuarine and coastal waters around Ireland. Journal of Plankton Research, 32 (1), pp. 99-118.

O’Reilly, J.E., Mueller, J.L., Mitchell, G.G., Kahru, M., Chavez, F.P., Strutton, Cota, G.F., Hooker, S.B., McClain, C.R., Carder, K.L., Muller-Karger, F., Harding, L., Magnuson, A., Phinney, D., Moore, G.F., Aiken, J., Arrigo, K.R., Letelier, R., Culver, M., 2000. Ocean color chlorophyll a algorithms for SeaWiFS OC2 and OC4, Version 4. In S. B. Hooker and E. R. Firestone (eds.), SeaWiFS post launch calibration and validation analysis, Part 3. NASA Technical Memo 2000-206892, V. 11, NASA Goddard Space Flight Center.

Pingree, R.D., Le Cann, B., 1989. Celtic and Armorican slope and shelf residual currents. Progress in Oceanography, 23, pp. 303-289.

Proctor, R., Holt, J.T., Anderson, T.R., Kelly-Gerreyn, B.A., Blackford, J., Gilbert, F., 2002. Towards 3-D ecosystem modelling of the Irish Sea. Proceedings of the International Conference on Estuarine and Coastal Modeling, pp.929-948

Raynolds, R.W., Smith, T.M., Liu, C., Chelton, D.B., Casey, K.S., SChl-ax, M.G., 2007. Daily High-Resolution-Blended Analyses for Sea Surface Temperature. Journal of Climate, 20, pp.5473-5495.

Reynolds, R. W., 2009. What's New in Version 2. OISST Webpage.http://www.ncdc.noaa.gov/sites/default/files/attachme nts/Reynolds2009_oisst_daily_v02r00_version2-features.pdf (4 March 2015).

Robson, J. Sutton, R., Lohmann, K., Smith, D., Palmer, M.D., 2012. Causes of the Rapid Warming of the North Atlantic Ocean in the Mid-1990s. J. Climate, 25, pp. 4116-4134.

Silke, J., O’Beirn, F., Cronin, M. 2005. Karenia mikimotoi: An exceptional dinoglagellate bloom in Western Irish Waters, Summer 2005. Marine Environment and Health Series, No 21, ISSN NO: 1649-0053.

Stumpf, R.P., Culver, M.E., Tester, P.A., Tomlinson, M., Kirkpatrick, G.J., Pederson, B.A., Truby, E., Ransibrahmanakul, V. and Soracco, M., 2003. Monitoring Karenia brevis blooms in the Gulf of Mexico using satellite ocean color imagery and other data. Harmful Algae, 2, pp. 147160.
Tanga, D, Kawamurab, H , Sang Ohc, I. and Bakerd, J., 2006. Satellite evidence of harmful algal blooms and related oceanographic features in the Bohai Sea during autumn 1998. Adv. Space Res., 37, pp. 681-689.

Xue, Y., Smith, T.M., Reynolds, R.W., 2003. Interdecadal Changes of 30-Yr SST Normals during 1871-2000. J. Climate, 16, pp. 1601-1612. 